\title{
Quality management and innovation: new insights on a structural contingency framework
}

\author{
Dara Schniederjans $^{1 *}$ and Marc Schniederjans ${ }^{2}$
}

\author{
* Correspondence: \\ mschniederjans1@unl.edu \\ ${ }^{1}$ Department of Marketing and \\ Supply Chain Management College \\ of Business Administration, \\ University of Rhode Island Kingston, \\ Kingston, RI 79409, USA \\ Full list of author information is \\ available at the end of the article
}

\begin{abstract}
With increasing market competition, organizations are striving for greater innovation in products and services. Quality management has the potential to invigorate an organization's product, process and administrative innovation when strategically aligned with internal contingencies. This paper seeks to address the relationship between social and technical quality management with innovation. Moreover, this paper empirically assesses contingency factors including organization size, task and managerial ethics which play roles in moderating the relationship between quality management and innovation. Based on an empirical study we find social quality management practices, not technical quality management practices, are positively associated with innovation. We also find a reciprocal positive relationship between social quality management and technical quality management. In addition our research reveals the positive relationship between quality management and innovation is moderated by the effects of organizational size, task and managerial ethics.
\end{abstract}

Keywords: Social quality management; Technical quality management; Innovation; Empirical research

\section{Background}

In an increasingly competitive environment, factors such as innovation and quality management can lead to competitive advantage. A recent survey of the Boston Consulting Group found that innovation was among the top three strategic priorities for $71 \%$ of companies [1]. This is in part due to innovation's being able to provide unique products and processes which create greater value for consumers as well as financial benefits for the organization [2]. Other research suggests quality management is a known driver of innovation in organizations. Quality management practices have also been associated with operational and financial performance allowing firms to achieve a sustainable competitive advantage ([2,3];).

The importance of innovation and quality management has motivated researchers to identify various driving forces of innovation and to seek new ways of creating it through quality management practices. The current research defining the relationship between quality management and invigorating innovation appears to possess some shortcomings.

First and foremost is the presentation of mixed results. While some studies found a positive association between quality management practices and innovation $[4,5]$ others showed no such connection [6,7]. We contend a reasonable explanation for these mixed results is due to a lack of understanding of potential contingency factors. To 
survive in a dynamic and competitive environment, organizations need practices that are aligned with their own individual organizations [3,8]. As such this study seeks to address several contingency factors using a theoretical basis of structural contingency theory. These factors include organizational size and task as well as managerial ethical evaluation.

Secondly, while some studies express the importance of managerial leadership as a basis for enhancing the value of quality management in innovation (e.g., [2]) there is limited development on this construct, especially when it comes to motivational factors like ethical evaluation. Thus we seek to also highlight the importance of managerial ethics (via managerial deontological and teleological evaluation) on improving innovation through quality management.

Third, prior research suggests the need for more studies to analyze the different dimensions of quality management on each other as well as on other variables like innovation [9]. We therefore distinguish two dimensions (social and technical) of quality management and seek to address their relationship with innovation. We also seek to assess the impact of quality management on various aspects of innovation including product, process and administrative innovation.

In summary this paper seeks to address the following questions: do quality management practices impact innovation, and more specifically, do social quality management practices (i.e., cross-functional cooperation, cross-training, long-term supply chain relationships) and technical quality management practices (i.e., just in time (JIT) manufacturing and design for manufacturing) impact innovation (i.e., radical and incremental product and process innovation and administrative innovation)? Do social quality management practices impact technical quality management practices and vice versa? Do certain contingency factors (i.e., organizational size, task and managerial ethical evaluation) play a role in the relationship between quality management and innovation?

To address these questions our paper is structured as follows: first, we present a brief literature review of quality management, innovation and our contingency factors. Next, we address our conceptual model and explain how structural contingency theory explains the relationships within the model. Then we discuss the results of our survey analysis. Finally, we address research and practical implications in our discussion and conclusion.

\section{Literature review}

Innovation

Innovation is broadly defined in business research literature. In general it is defined as new applications of knowledge, ideas, or methods which generate new capabilities and leverage competitive sustainability $[2,10,11]$. Current research takes into account that there are several types of innovation which require an organization to demonstrate unique and refined responses. As such we follow the work of Kim et al. [2] which characterizes five unique types of innovation: incremental product, incremental process, radical product, radical process and administrative. Previous research has validated these types of innovation empirically (e.g., [12-14]).

In this paper we delineate three classes of innovation: product, process and administrative. Product innovation refers to the technological innovation of the firm in developing novel products for consumers. Process innovation refers to the technological 
innovation of firms in their production processes. Both product and process innovation can be either radical or incremental. Radical innovation refers to the adoption of new technology in order to create demand that is not recognizable by markets [2]. Incremental innovation is minor changes to current technologies when it comes to design, function, price, quantity or other features to meet the needs of current customers [2]. Administrative innovation in contrast to technological innovation is often enhanced by internal needs for structure and coordination. Instead of a focus on the customer it focuses on internalized structures and systems.

Innovation has a long history of research addressing how to define it (e.g., [15]) or how to enhance it (e.g., [16]). In this study we focus on the latter of the two questions addressing the impact of quality management on innovation.

\section{Quality management practice}

Quality management like innovation is also a broadly defined topic. Most research, however, agree that the main goal of quality management is to improve and meet stakeholder needs by removing deficiencies including error and rework $[17,18]$. While a vast majority of studies view quality management practices as a single variable (e.g., [18]) other more recent studies delineate the various practices into multiple dimensions (e.g., [3]). In this study we characterize quality management into two different dimensions: social and technical practices.

Social quality management practices refer to quality management practices that are social/behavioral in nature. These practices have a focus toward involvement and commitment of management, employees, and supplier training, learning and cooperation or teamwork [3]. Previous studies have captured the social essence of quality management by a focus on internal social structures (e.g., cross functional cooperation) as well as external social structures (e.g., long-term supplier relationships). In this study we will focus on both by borrowing the three dimensions of Ketokivi and Schroeder [19]: quality training, cross-functional cooperation and long-term supply chain relationships. Quality training is the degree to which employees receive training to perform quality management tasks. Cross-functional cooperation refers to the degree to which different departments and individuals coordinate their quality activities and efforts. Long-term supply chain relationships refer to the degree to which the organization encourages development of recurring exchanges, supplier involvement and reliable information sharing with suppliers.

Technical quality management refers to the mechanical methods used by employees of an organization. It is generally defined as practices with a focus on controlling processes and products through tools for the purpose of conforming to and satisfying established requirements [3]. Previous literature defines technical quality management in a variety of ways including process management [20-22], preventative maintenance [23] and housekeeping [24]. In our study we define technical quality management through the lens of JIT and design for manufacturability which encompass each of these dimensions [19]. Just-in-time (JIT) refers to the degree to which the organization seeks to eliminate waste, minimize inventories through measures such as set up time reduction, frequent resupply and delivery and plant layout [19]. Design for manufacturability is the degree to which a plant's products are designed to reduce any complication in manufacturing through practices including simplified design and reduction of parts [19]. 
As previously mentioned prior research both confirmed and denied the relationship between quality management and innovation. Given this conflicting evidence we believe it is important to assess contingency factors which may govern this relationship. Structural contingency theory provides an adequate theoretical basis for guidance in distinguishing specific contingency factors that may impact this relationship.

\section{Structural contingency factors}

Structural contingency theory posits that an organization must strive to align the contingencies of the firm with factors in the external and internal environment [25]. Ultimately, the success of an organization depends on whether an organization's processes and practices fit with both environmental and internal practices [26-30]. Applied to the context of this paper we will examine the impact of quality management practices on innovation performance whose relationship will be determined by the three characteristics of organizational size, organizational task and managerial ethical evaluation.

Organizational size has been operationalized most often as the approximate number of employees of an organization [31,32]. This dimension is one of the two main contingencies that structural contingency theory considers. The other contingency is organizational task. Organizational task can be operationalized through task uncertainty and task interdependence [33]. Task uncertainty refers to the lack of information about how to perform a specific task [34]. Task interdependence is the degree to which individuals perceive that they interact with and depend on others in order to carry out their work [35]. Both organizational size and task have been well documented factors which play roles in establishing adequate fit for performance [25]. As such we will assess these factors in our model.

An often under-represented contingency, specifically for assessing quality management, is managerial ethical evaluation. While managerial leadership continues to be a well-documented construct and is also referred to as a necessity for establishing a myriad of performance dimensions via quality management, a lack of research provides for confusion toward motivational factors that might impact such a relationship. As such we will assess managerial ethical evaluation. Managerial ethical evaluation can be operationalized via teleological and deontological evaluation. Ethical judgments are determined by both teleological and deontological evaluations. Teleological evaluation is a function of the perceived consequences of each alternative for stakeholders, the probability that each consequence will occur for those stakeholders, and the desirability and importance of each consequence for the stakeholder [36]. Deontological evaluation is the process whereby an individual compares different alternatives with a set of predetermined deontological norms representing an individual's personal values or perceived moral obligations [36]. Previous research supports the strong association between an individual's ethical evaluations and actions.

\section{Hypotheses development}

According to structural contingency theory the goal of an organization and its managers should be fit which indicates consistency between a firm's processes and practices with contingency factors. Management should respond to this by developing, selecting and implementing quality management strategies to maintain fit with contingencies such as organizational size, task and their own ethical evaluations in order to enhance 
performance initiatives especially in the innovation domain. Quality managers should also understand various relationships between quality management practices in order to further knowledge of the complex dynamics which lead to innovation. As such we present our conceptual model in Figure 1.

\section{Quality management and innovation}

The prior research involving quality management and innovation has shown the positive association between certain quality management practices and innovation [4,5,9,37-39]. Other research has suggested that not all quality management practices relate to performance or innovation [22,40].

Understandably, researchers need to specify the type of quality management practice and how it impacts innovation. Social quality management has the potential to improve product innovation in a myriad of ways. Quality training enhances the skills of an employee to efficiently and effectively improve teamwork, thus reducing errors and enhancing job satisfaction which can impact product innovation [2]. Cross-functional cooperation enables open communication supporting creative idea suggestions which are essential to product innovation [3]. Further, promoting greater relationships within

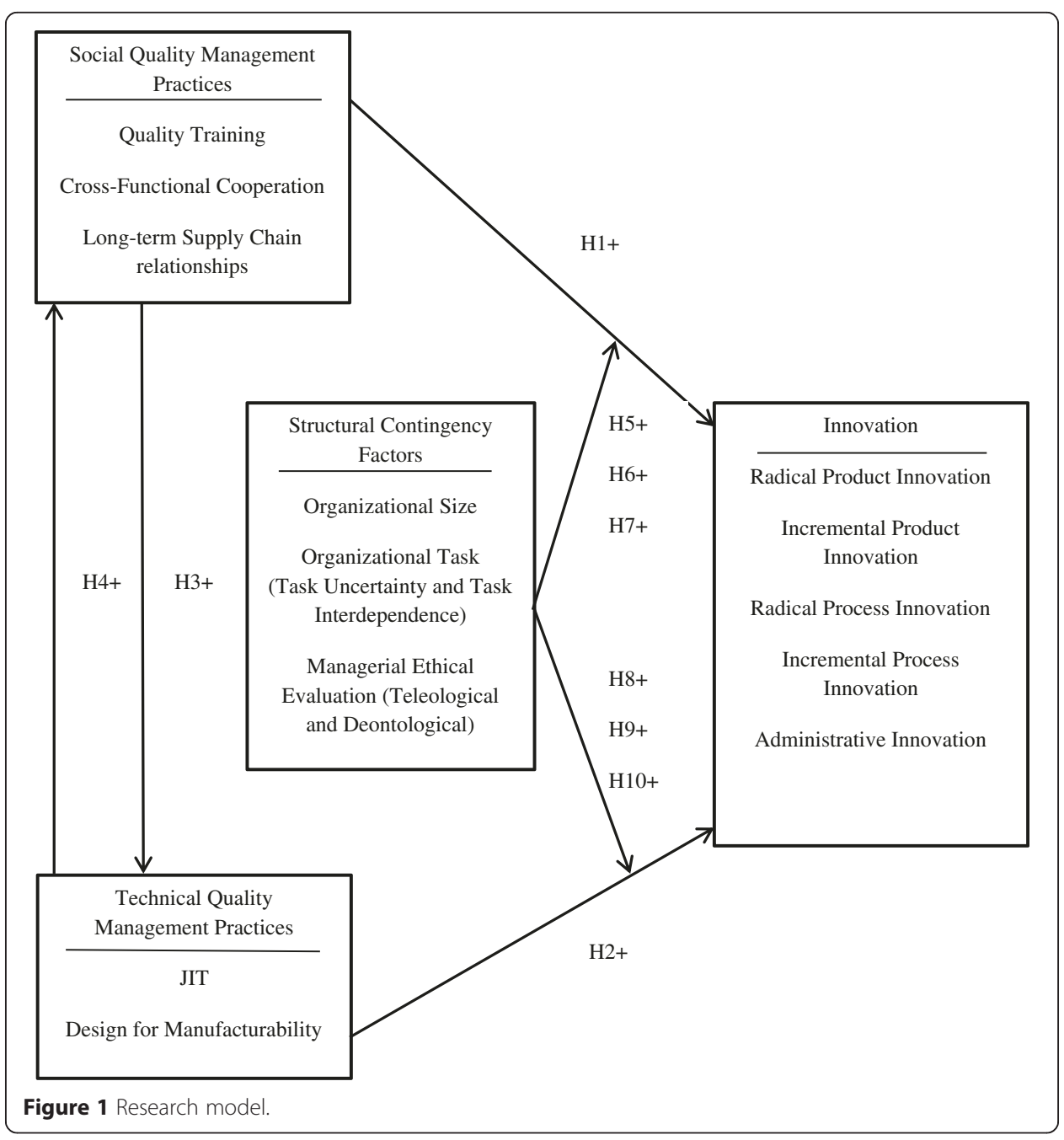


a supply chain network can result in greater information sharing about innovative products which enables a buying company to decrease product development time and put more effort toward developing product innovation [2].

Social quality management practices also have a unique potential to invigorate process quality. Quality training enhances employees' abilities to work efficiently and effectively further allowing them to recognize how to implement quality techniques and principles in quality management processes [2]. Cross-functional cooperation motivates employees to be involved in innovative design processes, developing teamwork and enhancing productivity essential to process design [41]. In addition long-term supply relationships are fundamental for obtaining high quality materials and leveraging unique knowledge and expertise to facilitate process innovation [42].

While social quality management has been linked to process and product innovation in previous literature, little work has been done regarding its association with administrative innovation. Social quality management has the potential to influence not only product and organizational processes, but also internal structures as well. For example, quality training helps establish teamwork, encourages creative ideas from all levels of employees, and promotes an information sharing climate enhancing internal innovation [43]. Cross functional cooperation on the other hand promotes employee involvement and teamwork allowing for a diverse group of individuals to collaborate and come up with innovative internal process ideas. Finally, the development of supplier relationship management enables organizations to exchange innovative ideas for new products, improves processes as well as enhances internal operations [2]. Suppliers can be involved with both product and process design which allows a buying organization to not only reduce time and costs, but also focus on strategic technology development $[2,44,45]$. Based on the previous literature we hypothesize:

H1. Social quality management practice is positively associated with innovation.

Along with social quality management technical quality management has also been assessed in terms of its impact on innovation. One important facet of JIT allows each employee key involvement in quality efforts dealing with quality data, designing products and managing processes [2]. Previous research suggests immediate and useful feedback from employees is instrumental for speeding a new product to the market which is applicable to product innovation $[43,46]$. Design for manufacturability can also promote innovation through simplification. While some expect simplification to be an impetus for de-innovation, finding new ways to reduce design problems in a product can be a form of product innovation in and of itself.

Both JIT and design for manufacturability require employees to focus on the continuous improvement of these processes. The focus on continuous improvement requires a level of process innovation in order to constantly strive for greater quality. MartinezCosta and Martinez-Lorente [9] found that the use of common quality management technical tools leads to both product and process innovation. Design for manufacturability suggests an efficient design is characterized by fewer standardized components enhancing process management, smaller process variance and less process complexity thereby enhancing process, product and even service innovation [44,47].

Administrative innovation can also be linked to technical quality management. Kim et al. [2] argues that implementing quality management (like JIT and Design for manufacturability) can not only help produce innovative products and processes, but also 
helps develop innovation plans internally. Effective management of processes can encourage firms to develop routines formed by a set of best practices thereby establishing a learning base for further innovative activities externally and internally [38]. Based on the previous research we hypothesize the following:

$\mathrm{H} 2$. Technical quality management practice is positively associated with innovation.

\section{Social and technical quality management practices}

The research pertaining to the relationships between different quality management practices is still in its infancy. However, given the conflicting findings on the association between quality management and innovation, it is imperative to not only define quality management adequately, but also assess the potential relationships between different practices which may impact this relationship. Previous research suggests that "soft" quality management practices including small group problem solving, employee suggestion and task-related training have a positive impact on "hard" quality management practices including process management and quality information [3].

The quality training aspect of social quality management provides a foundation for highly motivated employees with sufficient and effective problem solving abilities. This is needed for the adoption and utilization of JIT and design for manufacturability [3]. Cross functional cooperation also requires collection and dissemination between organizational functions in order to effectively enhance quality performance. It can nurture a corporate culture of autonomy, cooperation and teamwork which provides support for technical quality management. Cross functional cooperation informs operators and engineers about defective parts immediately so that corrective actions can be taken to remedy problems and reduce defects $[22,44]$. It can also identify non-value-added processes that helps employees when modifying and improving quality processes [44]. Further, supply chain network decisions should be aligned with decisions regarding simplified product design required for manufacturability [48]. Based on this previous research we hypothesize the following:

H3. Social quality management practices are positively associated with technical quality management practices.

While we agree with studies like Zeng et al. [3] who found social quality management practices are used as a basis for creating a climate suitable for technical quality management, there is also potential for a reciprocal relationship.

The continuous use of technical quality management practices can be used as a driver for social quality management especially if there is a focus on continuous improvement which JIT requires [49]. One of several facets of work improvement programs in JIT management is developing an organization with a focus on constant improvement requiring consistent quality management training as well as cross functional cooperation [50]. Moreover, JIT requires frequent resupply and delivery of materials, thus necessitating continuous improvement of supplier relationship management [19].

Design for manufacturability requires organizations to find new ways to simplify the design of their products and reduce part counts [19]. In order to do so employees need to be cognizant of design simplification strategies and tools, thus requiring a greater need for education and training. Additionally, new designs require greater customer relationship management skills making it mandatory for inter-functional cooperation between operations/engineering and marketing. Organizations may also seek out buyer 
development from suppliers in order to enhance product design. Thus, organizations seek out new ways to enhance their relationships with suppliers. Based on this previous research we hypothesize the following:

H4. Technical quality management practices are positively related to social quality management practices.

\section{Structural contingency}

There appears to be little research on specific contingency factors which may play roles in the often misrepresented relationship between quality management and innovation. Structural contingency theory provides a reasonable theoretical foundation to assess this relationship.

Structural contingency relies heavily on the premise that organizations should align their practices with contingency factors in order to promote greater performance. Two main contingency factors defined in structural contingency theory are organizational size and task [51]. For purposes of this paper we also include managerial ethical evaluation.

\section{Organizational size}

Organizational size, or the approximate number of employees in an organization, is adjacent to the number of personnel resources used to facilitate quality management in enhancing innovation. That is, the more individuals an organization has, the more likely it is to have enough human resources to maintain adequate levels of quality training, participate in cross-functional collaboration and cultivate greater relationships between buyers and suppliers. As evidenced by previous studies these social quality management practices can be used to improve products, processes, and administrative innovation [2,3,41,42].

Moreover, having a larger workforce also enhances the performance of technical quality management practices on perpetuating greater innovation. For example a larger workforce can offer greater insight in set up time reduction methods as well as maximizing the efficiency of the plant layout, thus potentially amplifying process and administrative innovation [2,38]. Moreover, full departments can be dedicated to maximizing the supply and delivery of materials leading to enhanced product innovation [2]. Based on this previous research we hypothesize the following:

H5. Organizational size moderates the positive association between social quality management practices and innovation.

H6. Organizational size moderates the positive association between technical quality management practices and innovation.

\section{Organizational task}

As mentioned previously organizational task is separated into two dimensions: task uncertainty and task interdependence. These two dimensions oppose each other in terms of the potential to facilitate innovation via quality management.

While task uncertainty is the lack of information about how to perform a specific task [34], in the context of this paper task uncertainty is defined as an employee's uncertainty in performing both social and technical quality management practices. This uncertainty can lead to a variety of problems in implementing social quality management thereby limiting its potential to increase all forms of innovation. If an 
individual has a lack of knowledge brought about by insufficient training, or if quality management trainers have inadequate knowledge of quality management tools, it is likely to hinder the relationship between quality training and innovation. Moreover, a lack of knowledge regarding tools used for cross-functional or supply chain information sharing can also hinder intra- and inter-organizational relationships which are valuable for enhancing product, process and administrative innovation [2,3,41,42,44,45].

Task uncertainty can also be a strong hindrance to the relationship between technical quality management and innovation. Both JIT and design for manufacturability require employees at all levels to have adequate and extensive knowledge of tools used for quality management purposes [52]. As such, task uncertainty can limit the effectiveness of both JIT and design for manufacturability on a variety of performance dimensions including product, process and administrative innovation.

While task interdependence is the degree to which employees perceive their interaction with and dependence on others to carry out work [35], in the context of this study it refers to the perception of employees regarding interaction and dependence on others (via internal and external stakeholders) to carry out quality management practices. Unlike task uncertainty, task interdependence can be used to facilitate performance in organizations. Social quality management practices including quality training, cross-functional cooperation and developing long-term relationships with suppliers require high levels of task interdependence between quality management employees and internal and external stakeholders [53]. A commonly held critical success factor of both JIT and design for manufacturability is teamwork [54]. Task interdependence helps build an environment conducive for teamwork [55] leading to effective quality management practices employment and consequently enhancing product, process and administrative innovation.

Based on previous research task uncertainty and task interdependence will have conflicting impacts on the relationship between quality management and innovation. While task uncertainty is likely to have a negative effect, task interdependence will likely have a positive impact on the relationship. In order to account for this task uncertainty will be assessed in terms of task certainty. In doing so we hypothesize the following:

H7. Organizational task moderates the positive association between social quality management practices and innovation.

H8. Organizational task moderates the positive association between technical quality management practices and innovation.

\section{Managerial ethics}

While structural contingency theory provides an adequate theoretical basis for explaining the impact of organizational size and task on the relationship between quality management and innovation, it is not without limitations. Critics hold that structural contingency theory is deterministic [56]. That is, an organization reacts to changes in its contingencies, which alter its environment and in turn changes its contingencies [51]. The theory argues that an organization's structure is determined solely by its situation [51]. However, previous research argues that managerial free choice opposes contingency theory [57]. It is thus important to take into account other potential contingencies related to managerial impact. Specifically, managers with adequate motivation have the potential to lead an organization in practices that increase 
organizational performance, despite external or structural contingencies [58]. Ethical evaluation has been shown to impact behavior and organizational performance [59]. We will add this contingency into the proposed model to help explain the relationship between quality management practices and innovation.

As previously stated managerial ethical evaluation can be operationalized via teleological and deontological evaluation. Teleological evaluation refers to an individual's perceived desirability and importance of a particular action's consequences [36]. In the context of this study it refers to a manager's perceived desirability and importance of consequences associated with conducting quality management. Very little research has been conducted on ethical evaluation and its ability to promote either quality management or be used as a contingency to promote the performance of quality management. However, an individual's positive teleological evaluation has been known to contribute to managerial motivation in performing tasks [60] in which motivation to perform impacts performance [58]. Thus, when people perceive positive consequences deriving from promoting quality training, cross functional cooperation, and long-term supplier relationships, they are likely to enhance their practice ultimately impacting performance. It will also facilitate the extensiveness of these social quality management practices leading to greater innovation as evidence from previous studies by Ahire and Ravichandran [41], Lemke et al. [42], Kim et al. [2], and Zeng et al. [3]. Similarly, perceived positive consequences from JIT and design for manufacturability may also enhance managerial motivation ultimately impacting the relationship between technical quality management practices and innovation performance.

While deontological evaluation is a person's perception of an action based one's own set of personal values and perceived moral obligations [36], in the context of this study it is a manager's perception regarding whether the use of quality management is aligned with personal values or moral obligations. An organization often shapes its strategy around certain moral obligations to its stakeholders [61]. Managers often believe they have fundamental moral obligations to stakeholders via their managerial roles [61]. This moral obligation can promote job involvement or performing job functions to one's utmost potential [62]. This includes enhancing both social and technical quality management practices. Quality management can greatly impact an organization's performance and often may have dire consequences if not adequately conducted. This is evidenced by situations including GM's reluctant recall of a defective ignition switch causing 13 deaths and 54 accidents [63]. Unfortunate events like this remind firms of top management's moral obligations to not only consumers, but also to internal and supply chain stakeholders as well. Positive deontological evaluation will help enhance managerial motivation to conduct quality management practices extensively, thus impacting product, process and administrative innovation as evidenced by previous literature $[4,5,9,37-39]$.

It is not within the confines of this article to argue that the adoption of quality management is an ethical decision. However, based on previous literature the impact of ethical evaluation on job involvement or motivation to perform is undeniable $[59,62]$. Further, motivation enhances managerial leadership which is a critical success factor in facilitating performance including innovation via quality management [2]. While ethical evaluation may not have a direct impact on quality management or innovation, it has 
been shown to enhance motivation which perpetuates individual action in facilitating performance. As such we hypothesize the following:

H9. Managerial ethical evaluation moderates the positive association between social quality management practices and innovation.

H10. Managerial ethical evaluation moderates the positive association between technical quality management practices and innovation.

\section{Method}

We chose to use survey analysis to empirically test our hypotheses for two reasons. First, survey research has the ability to generalize theoretically developed models to a larger population of interest with a known degree of accuracy [64]. Since our model is both theoretically supported by previous literature and structural contingency theory, the use of survey analysis to quantitatively examine the empirically questionable relationships is appropriate. Secondly, survey analysis allows us to gather sensitive information about organizational innovation and managerial ethical evaluation through an anonymous means.

\section{Questionnaire development}

The development of our survey was carried out in two steps: (1) collecting validated items from previous research and (2) large scale analysis. To ensure content validity a literature review was conducted to define each construct. Each question was assessed by experts in the fields of Operations Management and Business Ethics to ensure the reliability and validity of the scales. A total of 43 Likert-type scale questions were created. The question items are listed in Table 1.

\section{Sample}

Our conceptual model requires specific knowledge about an organization's quality management practices and how they impact innovation. It also requires general knowledge on decision makers' ethical evaluations. As such we chose to survey respondents at senior management levels. Since we also needed specific information on design for manufacturability and product innovation, we chose to use manufacturing organizations. An online survey organization was employed to collect data from these individuals. A total of 58 responses were collected. Characteristics of the respondents appear in Table 2. All respondents indicated their knowledge of the organizations' quality management practices and innovation strategies.

\section{Data analysis}

Partial Least Squares analysis (PLS) [65] was utilized for the analysis. PLS is useful in a context where subject sample sizes tend to be small. [66]. Also, PLS can model both reflective and formative constructs $[66,67]$. PLS allows parameters to be estimated independent of sample size [68]. It is best when used not only with small sample sizes but when assumptions of multivariate normality cannot be made, and when the concerned with the prediction of the dependent variable [69]. Wold [70] illustrated the low sample size requirement for PLS by analyzing a data set consisting of 10 observations. Chin and Newsted [71] also provide evidence using a Monte Carlo simulation where they found PLS path modeling approaches can provide information about the appropriateness of indicators at a sample size as low as 20 . 
Table 1 Questionnaire items

Items

Social quality management practices

Quality training

SQ1: Employees at this organization learn how to perform a variety of quality management tasks/jobs.

SQ2: Employees are quality management cross-trained at this organization so that they can fill in for others if necessary.

Cross-functional cooperation

SQ3: Direct labor employees are involved to a great extent on quality management before introducing new products or making product changes.

SQ4: We work in teams, with members from a variety of areas (marketing, manufacturing, etc.) to introduce new products.

Long-term supply chain relationships

SQ5: We strive to establish long-term relationships with suppliers.

SQ6: We maintain close communication with suppliers about quality considerations and design changes.

\section{Technical quality management practices}

$J I T$

tQM1: Our suppliers deliver to us on a just-in-time basis (where a part/service is received within the appropriate time it is needed and only when it is needed).

tQM2: We can depend upon on-time delivery from our suppliers.

tQM3: Management emphasizes the importance of setup time reduction.

tQM4: We have low setup times of equipment in our plant.

tQM5: We have low work-in-process inventory on the shop floor.

tQM6: When we have a problem on the production floor, we can identify its location easily.

Design for manufacturability

tQM7: We make an effort, in the design process, to list only the specifications which are really needed.

tQM8: The emphasis in part design is on minimizing the part count.

tQM9: The parts we produce are designed for ease in manufacturability and assembly.

\section{Structural contingency factors}

Organizational size

SC1: How large is your organization?

SC2: How many employees are in your organization?

Organizational task

Task uncertainty

SC3: Quality management is well understood in our organization.

SC4: Our employees are given enough information about quality management practices to adequately employ them.

SC5: Our organization understands how to incorporate quality management practices.

Task interdependence

SC6: I frequently coordinate my quality management efforts with others.

SC7: My own performance in quality management work is dependent on receiving accurate knowledge from others.

SC8: In order to do my work in quality management, I need to spend most of my time talking to other people.

\section{Source}

Ketokivi and Schroeder [19]

Ketokivi and Schroeder [19]

Lin and Huang [35]; Shang et al. [36]; Stock and Tatikonda [34] 
Table 1 Questionnaire items (Continued)

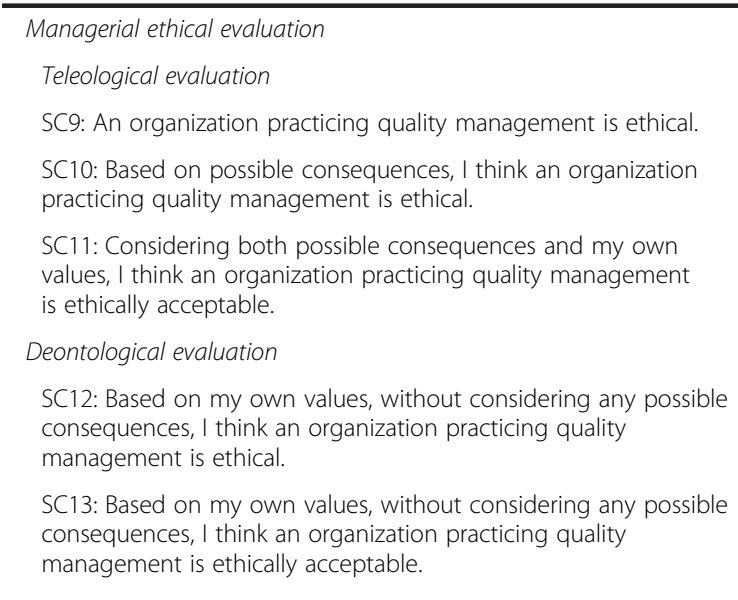

\section{Innovation}

Radical product innovation

INN1: Our new products differ substantially from our existing products.

INN2: We introduce radical product innovations into the new market more frequently than our competitors.

INN3: The percentage of total sales from radical product innovations is up substantially.

Incremental product innovation

INN4: Our new products differ slightly from our existing products.

INN5: We introduce incremental product innovations into the market more frequently than our competitors.

INN6: The percentage of total sales from incremental product innovations is up substantially.

Radical process innovation

INN7: Our organization has introduced new or significantly improved machinery and equipment for producing products or services.

INN8: Our organization has introduced new or significantly modified productive processes for producing products or services.

INN9: Our organization has introduced new or significantly improved information technologies for producing products or services.

Incremental process innovation

INN10: Our organization introduced minor or incrementally improved machinery and equipment for producing products or services.

INN11: Our organization introduced minor or incrementally modified productive processes for producing produce or services.

INN12: Our organization introduced minor or incrementally improved information technologies for producing products or services.

Administrative innovation

INN13: Our organization implemented new or improved existing computer-based administrative applications.

INN14: Our organization implemented new or improved existing employee reward/training schemes.

INN15: Our organization implemented new or improved existing structures such as project team or departmental structures, within or in-between existing structures.

Using Hulland [72] we analyzed the validity and reliability of the scales by assessing (1) construct/item reliability, (2) convergent validity and (3) discriminant validity. These results are presented in Table 3. To examine construct reliability we identified 
Table 2 Characteristics of respondents

\begin{tabular}{|c|c|}
\hline Demographic & Frequency (\%) \\
\hline \multicolumn{2}{|l|}{ Position (D1) } \\
\hline Owner/CEO/President & 68.6 \\
\hline Senior manager & 31.4 \\
\hline \multicolumn{2}{|l|}{ Size (SC2) } \\
\hline Very small organization (20 employees or less) & 7.8 \\
\hline Small organization (21-100 employees) & 27.5 \\
\hline Medium organization (101-500 employees) & 23.5 \\
\hline Large organization (over 500 employees) & 41.2 \\
\hline \multicolumn{2}{|l|}{ Age (D2) } \\
\hline $18-29$ years & 5.9 \\
\hline 30-44 years & 15.7 \\
\hline $45-60$ years & 43.1 \\
\hline Over 60 years & 35.3 \\
\hline \multicolumn{2}{|l|}{ Education (D4) } \\
\hline Less than high school degree & 2.0 \\
\hline High school degree & 3.8 \\
\hline Some college or Associate's degree & 31.4 \\
\hline Bachelor degree & 31.4 \\
\hline Graduate degree & 31.4 \\
\hline \multicolumn{2}{|l|}{ Location (D5) } \\
\hline New England & 3.9 \\
\hline Middle Atlantic & 3.9 \\
\hline East North Central & 25.5 \\
\hline West North Central & 9.8 \\
\hline South Atlantic & 2.2 \\
\hline East South Central & 13.7 \\
\hline West South Central & 9.8 \\
\hline Mountain & 11.9 \\
\hline Pacific & 19.6 \\
\hline
\end{tabular}

Table 3 Data analysis

\begin{tabular}{lllllllll}
\hline Construct & Cronbach's alpha & Composite reliability & SQM & tQM & OS & OT & ME & INN \\
\hline SQM & 0.851 & 0.887 & 0.755 & & & & & \\
tQM & 0.899 & 0.912 & 0.468 & 0.737 & & & & \\
OS & 0.985 & 0.992 & 0.018 & -0.036 & 0.993 & & & \\
OT & 0.839 & 0.861 & 0.635 & 0.652 & 0.068 & 0.728 & & \\
ME & 0.964 & 0.972 & 0.371 & 0.316 & 0.097 & 0.368 & 0.936 & \\
INN & 0.940 & 0946 & 0.475 & 0.434 & -0.059 & 0.490 & 0.449 & 0.737 \\
\hline
\end{tabular}

Note: Square root of AVE is listed on the diagonal.

Abbreviations: SQM: Social quality management; tQM: Technical quality management; OS: Organizational size; OT: Organizational task; ME: Managerial ethics; INN: Innovation. 
Cronbach's alphas. In order to be considered a reliable construct it is recommended that Cronbach's alphas exceed 0.7 [72,73]. All Cronbach's alphas exceeded 0.7 indicating no reliability problems.

To examine convergent validity we assessed composite reliability and average variance extracted (AVE). Previous research suggests acceptable levels of composite reliability be greater than 0.7 and values be greater than 0.5 for AVE [74-76]. All of our composite reliability and AVE values were above 0.7 and 0.5 , respectively indicating no problems with convergent validity

In order to assess for discriminant validity we compared the square root of the AVE with construct correlation coefficients and other measures [67-75]. As seen in Table 3 the square root of the AVE is larger with each constructs' correlation coefficient. Based on these results each of the constructs has acceptable reliability, convergent and discriminant validity.

Since the data were collected from single informants we assessed common method bias using Harman's [77] single factor test and a modified marker variable test [78-80]. Assessing the data using Harman's single factor approach we found no single factor emerged from a factor analysis of all survey items. No one factor accounted for the majority of the variance in the model with one factor explaining only 33\% [78]. In addition to the Harman's single factor approach we also performed Lindell and Whitney's [81] marker variable test. We assessed the correlation between a theoretically unrelated construct (marker variable) and the other constructs. The results from the model indicate that the marker variable did not have any significant influence on the endogenous latent variables. Based on these results we conclude that common method bias does not seem to be a limiting factor in this model.

We also assessed for non-response bias by conducting an analysis of the variance for differences between early and late responders. The differences were non-significant indicating non-response bias was not a problem in this study [82].

PLS does not provide an index for the validation of a theoretical model $[67,83]$. In order to assess goodness of fit Tenenhaus et al. [83] proposes assessing $R^{2}$ with a suggested cut-off value of 0.36 [84]. Our model exceeds the rigid cut-off with an $R^{2}$ value of 0.46 .

\section{Results}

We examined the statistical significance of the parameter estimates using bootstrap with replacement. Our results presented in Table 4 are based on a bootstrapping sample of 500. Hypothesis 3 and Hypothesis 4 were examined with two different models. There were no statistically significant differing results between the two models.

Hypothesis 1 examined the relationship between social quality management and innovation. The results supported that social quality management practices have a positive association with innovation in organizations $(\beta=0.489, \mathrm{p}<0.01)$. Hypothesis 2 examined the relationship between technical quality management practice and innovation. The results did not support that technical quality management practices have a positive association with innovation in organizations $(\beta=0.054, \mathrm{p}>0.10)$. Hypothesis 3 examined the relationship between social quality management practices and technical quality management practices. The results supported that social quality management practices are positively associated with technical quality management practices 
Table 4 Results of hypotheses tests

\begin{tabular}{llll}
\hline Hypothesis & Relationship & $\boldsymbol{\beta}$ & Significance \\
\hline 1 & $\mathrm{SQM} \rightarrow \mathrm{INN}$ & 0.491 & Significant \\
2 & $\mathrm{tQM} \rightarrow \mathrm{NNN}$ & 0.054 & Not significant \\
3 & $\mathrm{SQM} \rightarrow \mathrm{tQM}$ & 0.489 & Significant \\
4 & $\mathrm{tQM} \rightarrow \mathrm{SQM}$ & 0.490 & Significant \\
5 & $\mathrm{SQM} \times \mathrm{OS} \rightarrow \mathrm{NNN}$ & 0.151 & Not significant \\
6 & $\mathrm{tQM} \times$ OS $\rightarrow \mathrm{INN}$ & 0.891 & Significant \\
7 & $\mathrm{SQM} \times \mathrm{OT} \rightarrow \mathrm{NNN}$ & -0.518 & Significant \\
8 & $\mathrm{tQM} \times \mathrm{OT} \rightarrow \mathrm{NNN}$ & -0.247 & Not significant \\
9 & $\mathrm{SQM} \times \mathrm{ME} \rightarrow \mathrm{NNN}$ & -0.834 & Not significant \\
10 & $\mathrm{tQM} \times \mathrm{ME} \rightarrow \mathrm{NNN}$ & Significant \\
\hline
\end{tabular}

Abbreviations: SQM: Social quality management; tQM: Technical quality management; OS: Organizational size; OT: Organizational task; ME: Managerial ethics; INN: Innovation.

$(\beta=0.489, p<0.01)$. Further, the reciprocal relationship between technical quality management and social quality management was also found to be significant $(\beta=0.490$, $\mathrm{p}<0.01$ ) providing support for Hypothesis 4 .

Hypotheses 5-10 examined the moderating relationships between our structural contingency factors (organizational size, organizational task, and managerial ethics) and the relationships between social and technical quality management with innovation. Our results supported the moderating role organizational size has with the relationship between technical quality management and innovation $(\beta=0.891, \mathrm{p}<0.01)$ and the moderating role managerial ethics has between technical quality management and innovation $(\beta=0.219, \mathrm{p}<0.05)$. Thus, both Hypotheses 6 and 10 were supported. We found a significant negative moderating relationship organizational task has between social quality management and innovation $(\beta=-0.518, \mathrm{p}<0.10)$. Further, we found no significant moderating effects of organizational size $(\beta=0.151, p>0.10)$ or managerial ethics $(\beta=-0.834, p>0.10)$ with the relationship between social quality management and innovation. We also found no significant moderating relationship of organizational task between technical quality management and innovation $(\beta=-0.247, \mathrm{p}>0.10)$. Thus, Hypotheses 5, 7, 8 and 9 were not supported.

\section{Discussion/conclusions}

Our results provide support for the reciprocal relationship between social quality management practices and technical quality management practices. That is, social quality management practices enhance the use of technical quality management practices, and in turn the use of technical quality management enhances social quality management. In addition we found that social quality management enhances innovation. We also found that organizational size and managerial ethics positively moderate the relationship between technical quality management and innovation.

These results provide theoretical support for the relationship between social quality management and innovation as well as social contingency theory. The relationship between social quality management and innovation has been discussed and empirically validated in previous literature $[2,3,41,42]$. Our results further validate this positive association. Our results, however, provide theoretical support detailing the various types 
of social quality management and an overall consensus that it positively impacts product, process and administrative innovation. This finding further provides empirical support for technical brokering which suggests innovations come about through combining two or more ideas or concepts [85]. Social quality management increases the likelihood of organizational innovation through rapid sharing and dissemination of ideas within either a single or between multiple organizations. Our findings also provide further empirical support for structural contingency theory. We found both organizational size and organizational task moderate the relationship between practice and performance, but in different ways. This study contributes to social contingency theory research by empirically validating that another contingency factor (managerial ethics) enhances the relationship between technical quality management and innovation.

These results augment Operations Management knowledge as well. In the past it has been assumed and empirically validated that social quality management practices enhance the use of technical quality management [2]. Our results confirm a reciprocal relationship. After examining two different models it appears technical quality management is similarly positively associated with social quality management. From this it seems organizations can use both social and technical quality management practices to enhance one another. However, not all types of quality management practices appear to increase organizational innovation.

We found no significant relationship between technical quality management and innovation. Moreover, we did not find any significant moderating relationship of organizational size or managerial ethics between social quality management and innovation. We also found a significant negative moderating relationship of organizational task between social quality management and innovation and a slightly negative, but nonsignificant, moderating relationship of organizational task between technical quality management and innovation.

The finding that technical quality management does not have a significant positive association with innovation has an interesting managerial implication. Based on our results technical quality management seems to be positively associated with social quality management which has a strong association with innovation. This implies that although technical quality management may not have a direct association with innovation, it might indirectly impact innovation by encouraging social quality management. For example, JIT management requires on-time delivery from suppliers. The more on-time deliveries made, the greater is the likelihood of establishing a long-term relationship with suppliers and enhancing close communications, thus potentially impacting innovation through frequent information sharing between suppliers. Understandably, while technical quality management does not have a direct association with innovation, it should not sway operations managers from technical quality management practices, but rather they should understand the dynamics between the two types of quality management in order to increase innovation performance. It is recommended that future research address the association between social and technical quality management with different types of supply chain or operations management performance.

The lack of findings regarding the moderating roles of organizational size, organizational task and managerial ethics contradicts structural contingency theory and ethics theory. It appears organizational size and task did not moderate the relationship between social and technical quality management with innovation. While structural 
contingency theory provides strong support for these contingency factors, they may not moderate the relationship between all types of practices and performance. For example many small organizations may spend time maintaining constant contact with their suppliers, thereby enhancing opportunities for organizational innovation. In addition high levels of managerial task certainty may actually negatively impact the relationship between both social and technical quality management and innovation. A manager who believes quality management is well understood by employees may reduce the likelihood of an organization implementing new or improved employee reward/training schemes fundamental for innovation. Future research should further explore these contradictory findings by using a larger sample size.

Another surprising finding is the lack of a moderating role that managerial ethics has between social and technical quality management practices with innovation. This finding contradicts previous research in ethics theory which suggests the importance of ethical evaluation in decision making and behavior ([59-62];). Perhaps the reasoning behind this finding lies in the definition of social and technical quality management practices. Quality management is fundamental not only on a managerial level, but also among lower level employees. Employees at all levels must work together with teams to establish long-term relationships with suppliers. A manager's ethical stance about quality management may have little or no impact on the actual relationship between social and technical quality management practices of lower level employees and firm innovation. On the other hand a manager that is highly motivated to implement quality management practices (via a high moral stance toward high quality) may actually limit an employee's ability to work with teams to find new ways to innovate because of a need to exercise control. Social quality management unlike technical quality management focuses on employee empowerment which enhances innovation. However, when management controls the actions of employees, employee empowerment is hindered, hindering teamwork and thereby innovation. Future research should further explore this surprising finding. Perhaps surveying all levels of employees would be an interesting undertaking.

Competing interests

The authors declare that they have no competing interests.

Authors' contributions

DGS and MJS jointly developed the research study, performed the analysis, and drafted the manuscript. Both authors have read and approved the final manuscript.

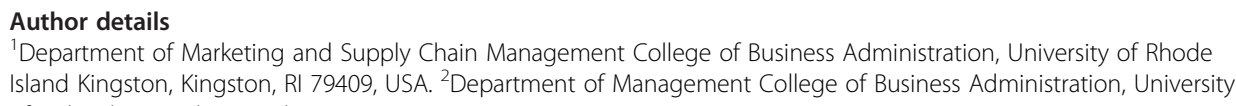

1. Slater SF, Mohr J, Sengupta S (2014) Radical product innovation capability: literature review, synthesis and illustrative research propositions. J Prod Innov Manag 31(3):552-566

2. Kim DY, Kumar V, Kumar U (2012) Relationship between quality management practices and innovation. J Oper Manag 30:295-315

3. Zeng J, Phan CA, Matsui Y (2015). The impact of hard and soft quality management on quality and innovation performance: An empirical study. International Journal of Production Economics, In press 162:216-226.

4. Feng J, Prajogo DI, Tan KC, Sohal AS (2006) The impact of TQM practices on performance: a comparative study between Australian and Singaporean organizations. Eur J Innov Manag 9(3):269-278 
5. Abrunhosa A, Moura E, Sa P (2008) Are TQM principles supporting innovation in the Portuguese footwear industry? Technovation 28(4):208-221

6. Singh PJ, Smith A (2004) Relationship between TQM and innovation: an empirical study. J Manuf Technol Manag 15(5):394-401

7. Santos-Vijande M, Alvarez-Gonzalez L (2007) Innovativeness and organizational innovation in total quality oriented firms: the moderating role of market turbulence. Technovation 27(9):514-532

8. Gibson BC, Birkinshaw J (2004) The antecedents, consequences, and mediating role of organizational ambidexterity. Acad Manag J 47(2):209-226

9. Martinez-Costa M, Martinez-Lorente AR (2008) Does quality management foster or hinder innovation? an empirical study of spanish companies. Total Qual Manag Bus Excell 19(3):209-221

10. Daft RL (1978) A dual-core model of organizational innovation. Acad Manag J 21(2):193-210

11. Andersson M, Lindgren $R$, Henfridsson $O$ (2008) Architectural knowledge in inter-organizational IT innovation. J Strateg Inf Syst 17(1):19-38

12. Chandy RK, Tellis GJ (1998) Organizing for radical product innovation: the over looked role of willingness to cannibalize. J Mark Res 35(4):474-487

13. Salavou H, Lioukas S (2003) Radical product innovations in SMEs: the dominance of entrepreneurial orientation. Creat Innov Manag 12(2):94-108

14. Di Benedetto CA, DeSarbo WS, Song M (2008) Strategic capabilities and radical innovation: an empirical study in three countries. IEEE Trans Eng Manag 55(3):420-433

15. Johannessen JA, Olsen B, Lumpkin GT (1998) Innovation as newness: what is new, how new, and new to whom? Eur J Innov Manag 4(1):20-31

16. Hurley RF, Hult GTM (1998) Innovation, market orientation, and organizational learning: an integration and empirical examination. J Mark 62(3):42-54

17. Juran JM, Godfrey AB (1998) Juran's quality handbook, 5th edn. McGraw-Hill Professional, New York, NY

18. Kull TJ, Wacker JG (2010) Quality management effectiveness in Asia: the influence of culture. J Oper Manag 28(3):223-239

19. Ketokivi MA, Schroeder RG (2004) Strategic, structural contingency and institutional explanations in the adoption of innovative manufacturing practices. J Oper Manag 22:63-89

20. Saraph JV, Benson PG, Schroeder RG (1989) An instrument for measuring the critical factors of quality management. Decis Sci 20(4):810-829

21. Anderson JC, Rungtusanatham M, Schroeder RG, Devaraj S (1995) A path analytic model of a theory of quality management underlying the Deming management method: preliminary empirical findings. Decis Sci 26(5):637-658

22. Flynn BB, Schroeder RG, Sakakibara S (1995) The impact of quality management practices on performance and competitive advantage. Decis Sci 26(5):659-691

23. Arauz R, Matsuo H, Suzuki H (2009) Measuring changes in quality management: an empirical analysis of Japanese manufacturing companies. Total Qual Manag Bus Excell 20(12):1337-1374

24. Schonberger RJ (2007) Japanese production management: an evolution with mixed success. J Oper Manag 25(2):403-419

25. Donaldson $L$ (2001) The contingency theory of organizations. Sage, Thousand Oaks, CA

26. Lawrence PR, Lorsch JW (1967) Organization and environment. Harvard University Press, Cambridge, MA

27. Thompson JD (1967) Organizations in action. McGraw-Hill, New York, NY

28. Nadler D, Tushman M (1980) A model for diagnosing organizational behavior. Organ Dyn 9:35-51

29. Scott WR, Cole R (2000) Introduction. In: Cole R, Scott WR (eds) The quality movement and organizational theory. Sage, Thousand Oaks, CA

30. Flynn BB, Huo B, Zhao X (2010) The impact of supply chain integration on performance: a contingency and configuration approach. J Oper Manag 28:58-71

31. Pugh DS, Hickson DJ, Hinings CR, Turner C (1969) The contexts of organizational structure. Adm Sci Q 14:91-114

32. Pugh DS, Hinings CR (1976) Organizational structure: extensions and replications: the aston programme II. Saxon House, Farnborough, England

33. Graubner M (2006) Task, firm size, and organizational structure in management consulting: an empirical analysis from a contingency perspective. Deutscher Universitats-Verlag, Germany

34. Stock GN, Tatikonda MV (2008) The joint influence of technology uncertainty and interorganizational interaction on external technology integration success. J Oper Manag 26(1):65-80

35. Lin TC, Huang CC (2008) Understanding knowledge management system usage antecedents: an integration of social cognitive theory and task technology fit. Information Manag 45(6):410-417

36. Shang RA, Chen YC, Chen DC (2008) Ethical decisions about sharing music files in the P2P environment. J Bus Ethics 80:349-365

37. Hoang DT, Igel B, Laosirihongthong T (2006) The impact of total quality management on innovation: findings from a developing country. Int J Qual Reliability Manag 23(8-9):1092-1117

38. Perdomo-Ortiz J, Gonzalez-Benito J, Galende J (2006) Total quality management as a forerunner of business innovation capability. Technovation 26(10):1170-1185

39. Prajogo DI, Hong SW (2008) The effect of tQM on performance in R\&D environments: a perspective from South Korean firms. Technovation 28(12):855-863

40. Ravichandran T, Rai A (2000) Quality management in systems development: an organizational system perspective. MIS Q 24(3):381-415

41. Ahire SL, Ravichandran T (2001) An innovation diffusion model of TQM implementation. IEEE Trans Eng Manag 48(4):445-464

42. Lemke F, Goffin K, Szwejczewski M (2003) Investigating the meaning of supplier-manufacturer partnerships. Int J Phys Distrib Logist Manag 33(1):12-35

43. Flynn BB, Schroder RG, Sakakibara S (1994) A framework for quality management research and an associated measurement instrument. J Oper Manag 11(4):339-366

44. Kaynak $\mathrm{H}$ (2003) The relationship between total quality management practices and their effects on firm performance. J Oper Manag 21(4):405-435 
45. Zu X, Fredendall LD, Douglas TJ (2008) The evolving theory of quality management: the role of six sigma. J Oper Manag 26(5):630-650

46. Miller R (1995) Applying quality practices in R\&D. Res Technol Manag 38(2):47-54

47. Ahire SL, Dreyfus $P$ (2000) The impact of design management and process management on quality: an empirical examination. J Oper Manag 18(5):549-575

48. Fixson SK (2005) Product architecture assessment: a tool to link product, process, and supply chain design decisions. J Oper Manag 23(3-4):345-369

49. Bond TC (1999) The role of performance measurement in continuous improvement. Int J Oper Produc Manag 19(12):1318-1334

50. Lea R, Parker B (1989) The JIT spiral of continuous improvement. IMDS 4:10-13

51. Miles JA (2012) Management and organization theory. Jossey-Bass, San Francisco, CA

52. Siemsen E, Roth AV, Balasubramanian S (2008) How motivation, opportunity, and ability to drive knowledge sharing: the constraining-factor model. J Oper Manag 26(3):426-445

53. Wageman R (2012) The meaning of interdependence. In: Turner M (ed) Groups at work: theory and research. Routledge, New York, NY

54. Salaheldin SI (2008) Critical success factors for TQM implementation and their impact on performance of SMEs. Int J Product Perform Manag 58(3):215-237

55. Ramamoorthy N, Flood PC (2004) Individualism/collectivism, perceived task interdependence and teamwork attitudes among Irish blue-collar employees: a test of the main and moderating effects. Human Relations 57(3):347-366

56. Perrow C (1984) Normal accidents: living with high-risk technologies. Basic Books, New York, NY

57. Schreyogg G (1980) Contingency and choice in organization theory. Organ Stud 1:305-326

58. Yukl G (1989) Managerial leadership: a review of theory and research. J Manag 15(2):251-289

59. Hunt SD, Vitell S (1986) A general theory of marketing ethics. J Macrmarketing 6(Spring):5-16

60. Hunt SD, Vasquez-Parraga AZ (1993) Organizational consequences, marketing ethics, and salesforce supervision. $J$ Mark Res 30:78-90

61. Berman SL, Wicks AC, Kotha S, Jones TM (1999) Does stakeholder orientation matter? the relationship between stakeholder management models and firm financial performance. Acad Manag J 42(5):488-506

62. Kolodinsky RW, Giacalone RA, Jurkiewicz CL (2008) Workplace values and outcomes: exploring personal, organizational, and interactive workplace spirituality. J Bus Ethics 81:465-480

63. Morran, C. (2015). GM ignition death toll rises again, now at 90. http://consumerist.com/2015/04/27/gm-ignitiondeath-toll-rises-again-now-at-90/. Accessed April 30, 2015.

64. Dale A (2006) Quality issues with survey research. Int I Social Res Methodol 9(2):143-158

65. Ringle CM. Wende S, Will S (2005). Smart PLS 2.0 M3 Beta. Available at: http://www.Smartpls.de (accessed 19 September 2014).

66. Peng DX, Lai F (2012) Using partial least squares in operations management research: a practical guideline and summary of past research. J Oper Manag 30(6):467-480

67. Chin WW (1998) The partial least squares approach to structural equation modeling. In: Marcoulides GA (ed) Modern methods for business research. Lawrence Erlbaum Associates Inc., Mahwah, NJ, pp 295-336

68. Graham JL, Mintu AT, Rodgers W (1994) Explorations of negotiation behaviors in ten foreign cultures using a model developed in the United States. Manag Sci 40(1):72-95

69. Birkinshaw J, Morrison A, Hulland J (1995) Structural and competitive determinants of a global integration strategy. Strateg Manag J 16(8):637-655

70. Wold HO (1989) Introduction to the second generation of multivariate analysis. In: Wold HO (ed) Theoretical empiricism: a general rationale for scientific model-building. Paragon House, New York, NY, pp VII-XL

71. Chin WW, Newsted PR (1999) Structural equation modeling analysis with small samples using partial least squares. In: Hoyle RH (ed) Statistical strategies for small sample research. Sage, Thousand Oaks, CA, pp 307-342

72. Hulland J (1999) Use of partial least squares (PLS) in strategic management research: a review of four recent studies. Strateg Manag J 20:195-204

73. Carmines EG, Zeller RA (1979) Reliability and validity assessment. Sage, Beverly Hills, CA

74. Nunnally JC (1978) Psychometric theory. McGraw Hill, New York

75. Fornell C, Larcker DF (1981) Evaluating structural equation models with unobservable variables and measurement error. J Mark Res 18:39-50

76. Bagozzi RP, Yi Y (1988) On the evaluation of structural equation models. J Acad Mark Sci 16:74-94

77. Harman HH (1967) Modern factor analysis. University of Chicago Press, Chicago, IL

78. Podsakoff PM, Organ D (1986) Reports in organizational research: problems and prospects. J Manag Stud 27:305-327

79. Podsakoff PM, Mackenzie SB, Lee JY, Podsakoff NP (2003) Common method biases in behavioral research: a critical review of the literature and recommended remedies. J Appl Psychol 88:879-903

80. Ronkko M, Ylitalo J (2011). PLS marker variable approach to diagnosing and controlling for method variance. Research Methods and Philosophy, ICIS 2011 Proceedings. Shanghai, China.

81. Lindell MK, Whitney DJ (2001) Accounting for common method variance in cross-sectional research designs. J Appl Psychol 86:114-121

82. Armstrong JS, Overton TS (1977) Estimating nonresponse bias in mail surveys. J Mark Res 14:396-402

83. Tenenhaus M, Vinzi VE, Chatelin YM, Lauro C (2005) PLS path modeling. Comput Stat Data Anal 48:159-205

84. Perols J, Zimmerman C, Kortmann S (2013) On the relationship between supplier integration and time-to-market. J Oper Manag 31:153-167

85. Hargadon A (2003) How breakthroughs happen: the surprising truth about how companies innovate. Harvard Business School Press, Boston, MA 